\title{
Sensorless Control of Doubly-Fed Induction Generators Based on Stator High Frequency Signal Injection
}

\author{
David Reigosa, Fernando Briz, Cristian Blanco, Juan Manuel Guerrero \\ University of Oviedo. Dept. of Elect., Computer \& System Engineering, Gijón, 33204, Spain. \\ reigosa@,isa.uniovi.es, fernando@,isa.uniovi.es, blancocristian@uniovi.es, guerrero@,isa.uniovi.es
}

\begin{abstract}
High frequency signal injection based methods have been widely investigated for sensorless position/speed control of induction machines (IMs), permanent magnet synchronous machines (PMSMs) and more recently for doubly fed induction generators (DFIGs). When used with IMs and PMSMs, the high frequency signal is injected in the stator windings, an asymmetric (salient) rotor being required for this case. Contrary to this, both stator and rotor terminals are accessible and sensored in DFIGs, being therefore possible to inject the high frequency signal either in the stator or the rotor terminals. As consequence of this, the method can be used even if the machine is non-salient. In the implementation of the method with DFIGs, the high frequency voltage signal is typically injected in the rotor, the high frequency components (voltages of currents) induced in the stator being used for rotor position estimation. A drawback of this alternative is that the method is sensitive to the grid impedance in the stator side, which will be affected by the grid configuration, and is normally unknown. This paper proposes the sensorless control a DFIG injecting the high frequency voltage in the stator side, and using a high frequency current cancellation strategy in the rotor side. The main advantage of the proposed strategy is that the estimated position is independent of the grid characteristics. ${ }^{1}$

Index Terms - DFIG, high frequency signal injection, sensorless control.
\end{abstract}

\section{Introduction}

The wind power generation has increased during the last years, significantly contributing the reduction of carbon dioxide emission and therefore to a lower environmental pollution [1-3]. This increase is expected to be continued as countries are putting forward their renewable action plans $[2$, $3]$, making the wind power generation to take a continuously increasing share of the power generation worldwide. Among the various types of grid connected wind turbines, the DFIGs are the more extended in on-shore applications, accounting for around of $50 \%$ of the installed wind turbines all over the world [4]. DFIGs have some appealing properties compared with other types of grid connected wind turbines: four quadrant active and reactive power capabilities; a fractional power converter compared to the machine rating $(\approx 30 \%)$, a certain ride through capability and operation above and below synchronous speed [1,5-7].

1 This work was supported in part by the Research, Technological Development and Innovation Programs of the Ministry of Science and Innovation under grant MICINN-10-CSD2009-00046 and of the Spanish Ministry of Science and Innovation-ERDF under grants MICINN-10ENE2010-14941 and MICINN-10-IPT-370000-2010-15.
Due to their increased use in the wind power generation, development of control techniques for DFIGs has received significant attention during the last years. In this context, implementation of sensorless control of the wind turbine is highly appealing as it results in a reliability increase and a cost reduction $[6,8]$. Sensorless control can be of special interest in low power wind turbines, where the speed/position sensor cost can account for a significant portion of the overall cost; in high power wind turbines, where the sensor cost could be less relevant, other relevant advantages can also exist. E.g. hollow shaft machines require special sensor designs, which are significantly more expensive, more difficult to install and less robust. Therefore, elimination of the position/speed sensor, cabling and connectors will be advantageous in terms of reliability and cost.

Sensorless control of AC machines has been the focus of significant research efforts during the last years [8-21, 28], the proposed methods being primarily focused on IMs and PMSMs [8-17]. These techniques can be roughly classified into fundamental excitation based methods and high frequency signal injection based methods. Fundamental excitation based methods have been extensively studied, and operate well in the mid-high speed region where the backEMF signal is large enough. However, the accuracy of these methods reduces as the speed does, due to the direct relationship between the back EMF and the speed, eventually they cannot work at very low or zero speed, neither in position control [9-10]. To overcome the limitations of the fundamental excitation based methods in the low speed region, high frequency signal injection based methods have been proposed. When used with IMs and PMSMs [6, 8, 1117], the high frequency signal is injected into the stator terminals via the inverter. The use of the PWM commutations [12], as well as the injection of a high frequency periodic signal on top the fundamental excitation (rotating [8, 13-16], pulsating [13-16] and square-wave [17]) have been proposed for this purpose. One key issue for the implementation of these methods with IMs and PMSMs is that the machine has to be salient. The interaction between the injected high frequency voltage and the rotor saliencies will modulate the resulting high frequency stator currents, the rotor position being obtained by signal processing of the resulting currents. One of the major limitations of saliency tracking based sensorless control techniques when used with PMSM and IM 
is their sensitivity to secondary saliencies and cross coupling effects due to saturation [14-16].

Contrary to IMs and PMSMs, both the stator and rotor terminals are accessible in DFIGs, with the rotor typically fed by the rotor-side-converter (RSC), the stator being directly connected to the grid (see Fig. 1). It is noted from Fig. 1 that the grid side converter connecting the rotor to the grid, operates in parallel with the stator. Thanks to this, injecting the high frequency signal either in the stator or the rotor terminals is feasible [6]. This opens interesting possibilities for the implementation of high frequency signal injection based sensorless methods for DFIGs. First and most important, DFIGs are not required to have a salient rotor for their use with these methods. Second, secondary saliencies, mainly saturation induced saliencies, do not have a significant impact on the method, what is a major advantage compared to IMs and PMSMs [14-16].

In the method proposed in $[6,18]$ for the sensorless control of DFIGs, the high frequency signal was injected in the rotor, two different options were studied to estimate the rotor position; 1) measuring the phase shift between the injected rotor high frequency current vector and the high frequency voltage vector induced in the stator [6], and 2) measuring the phase shift between the injected rotor high frequency voltage vector and the high frequency voltage vector induced in the stator [18]. One concern in both cases is the dependence of the results on the grid impedance, which is unknown and can vary depending on the grid condition.

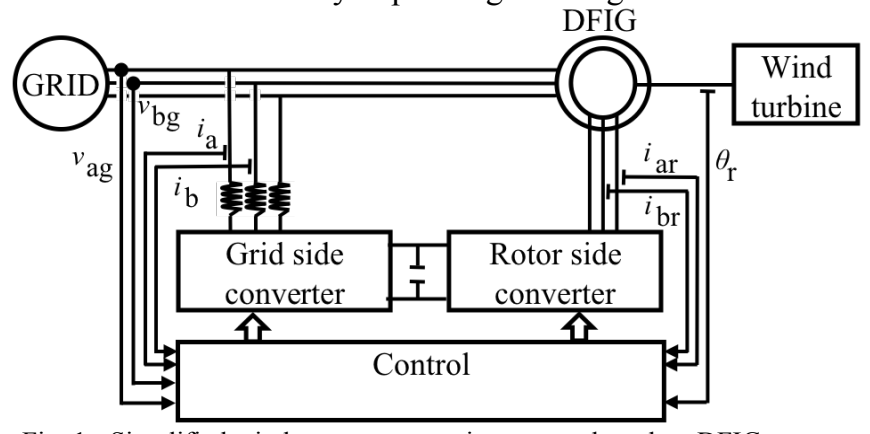

Fig. 1.- Simplified wind energy conversion system based on DFIG.

To overcome the effects of the grid impedance, the injection of a high frequency voltage in the stator terminals using the grid-side-converter (GSC) is proposed in this paper. A high frequency current cancellation strategy using the RSC will be used in the rotor side. A high frequency current regulator will be used for this purpose. The output voltage of this regulator will be shown to be modulated by the rotor angle, from which it is possible to estimate the rotor position.

The main advantage of the proposed method over model based sensorless methods [28], is its insensitivity to machine parameters variation. Compared to previously published high frequency signal injection based methods $[6,18]$, the proposed method shows a reduced sensitivity to machine and grid parameters variation.

The paper is organized as follow: the high frequency model of the DFIG and the physical principles of the method are presented in sections II and III, simulation and experimental results to confirm the viability of the method are provided in sections IV, V and VI. Finally, conclusions are presented in section VII.

\section{High frequency model of a DFIG.}

The high frequency model of a DFIG in a stationary $q d$ reference frame can be expressed as shown in (1)-(4) $[6,22]$. This model assumes that the frequency of the high frequency signal is significantly higher than the fundamental frequency (i.e. $\omega_{h f}>\omega_{r}$ ).

$$
\begin{aligned}
& v_{d s}^{s}=r_{s} i_{d s}^{s}+\left(L_{l s}+L_{m}\right) \frac{d i_{d s}^{s}}{d t}+L_{m} \frac{d i_{d r}^{s^{\prime}}}{d t} \\
& v_{q s}^{s}=r_{s} i_{q s}^{s}+\left(L_{l s}+L_{m}\right) \frac{d i_{q s}^{s}}{d t}+L_{m} \frac{d i_{q r}^{s^{\prime}}}{d t} \\
& v_{d r}^{s^{\prime}}=r_{r}^{\prime} i_{d r}^{s^{\prime}}+\left(L_{l r}^{\prime}+L_{m}\right) \frac{d i_{d r}^{s^{\prime}}}{d t}+L_{m} \frac{d i_{d s}^{s}}{d t} \\
& v_{q r}^{s^{\prime}}=r_{r}^{\prime} i_{q r}^{s^{\prime}}+\left(L_{l r}^{\prime}+L_{m}\right) \frac{d i_{q r}^{s^{\prime}}}{d t}+L_{m} \frac{d i_{q s}^{s}}{d t} \\
& r_{r}^{\prime}=\left(N_{s} / N_{r}\right)^{2} r_{r} \\
& L_{l r}^{\prime}=\left(N_{s} / N_{r}\right)^{2} L_{r} \\
& i_{q d r}^{s^{\prime}}=\left(N_{s} / N_{r}\right) i_{q d r}^{s} \\
& v_{q d r}^{s^{\prime}}=\left(N_{s} / N_{r}\right) v_{q d r}^{s} \\
& f_{q d}=2 / 3 *\left(f_{a}+f_{b} * e^{j * 2 * \pi / 3}+f_{c} * e^{j^{*} 4 * \pi / 3}\right)
\end{aligned}
$$

where $r_{s}$ is the stator resistance, $r_{r}^{\prime}$ is the rotor resistance referred to the stator (5), $L_{l s}$ is the stator leakage inductance, $L_{l r}^{\prime}$ is the rotor leakage inductance referred to the stator (6), $L_{m}$ is the magnetizing inductance, $i_{q d s}^{s}$ is the stator current complex vector, $i_{q d r}^{s^{\prime}}$ is the rotor current complex vector referred to the stator (7), $v_{q d s}^{s}$ is the stator voltage complex vector and $v_{q d r}^{s^{\prime}}$ is the rotor voltage complex vector referred to the stator (8), $r_{r}$ is the rotor resistance, $v_{q d r}^{s}$ is the rotor voltage complex vector, $i_{q d r}^{s}$ is the rotor current complex vector, $N_{s}$ is the stator number of turns, $N_{r}$ is the rotor number of turns. The transformation from three-phase quantities to qd quantities is given by (9).

\section{High frequency signal injection and rotor position estimation.}

High frequency signal injection sensorless control methods superimpose some form of high frequency signal to the fundamental excitation [8, 13-16, 18], rotating [8, 13-16, 18], sinusoidal pulsating [13-16] and square-wave [17] waveshapes being the most commonly used signals.

For all the analysis presented in this paper, a rotating high frequency signal (10) will be used, with $\omega_{h f}$ being the frequency of the injected signal and $V_{h f}$ the voltage magnitude of the injected high frequency signal. It is noted however that the method is easily extensible to the other forms of high frequency excitations [6]. 


$$
v_{d q h f}^{s}=V_{h f} e^{j \omega_{h f} t}
$$

If (10) is injected in the stator terminals of a DFIG via the GSC and assuming a rotor high frequency current cancellation strategy, -i.e. the rotor high frequency current is regulated to be zero-, the high frequency model (1)-(4) can be simplified to (11)-(14).

$$
\begin{aligned}
& v_{d s}^{s}=r_{s} i_{d s}^{s}+\left(L_{l s}+L_{m}\right) \frac{d i_{d s}^{s}}{d t} \\
& v_{q s}^{s}=r_{s} i_{q s}^{s}+\left(L_{l s}+L_{m}\right) \frac{d i_{q s}^{s}}{d t} \\
& v_{d r}^{s}=L_{m} \frac{d i_{d s}^{s^{\prime}}}{d t} \\
& v_{q r}^{s}=L_{m} \frac{d i_{q s}^{s^{\prime}}}{d t}
\end{aligned}
$$

where $i_{q d s}^{s^{\prime}}$ is the stator current complex vector referred to the rotor $\left(i_{\text {ads }}^{s^{\prime}}=\left(N_{r} / N_{s}\right) i_{a d s}^{s}\right)$.

Assuming that the machine operates in steady state, -i.e. the fundamental excitation frequency and/or speed changes relatively slowly compared to the high frequency signal-, the resulting stator high frequency current (15) and the induced rotor high frequency voltage (16) can be obtained from (11)(14).

$$
\begin{aligned}
& i_{d q h f_{-} s}^{s}=\frac{V_{h f}}{\left|Z_{h f}^{s}\right|} e^{j\left(\omega_{h f} t-\varphi_{Z f_{f}}\right)} \\
& v_{d q h f_{-} r}^{s}=\frac{N_{r}}{N_{s}} \frac{V_{h f}}{\left|Z_{h f}^{s}\right|} L_{m} \omega_{h f} e^{j\left(\omega_{h f} t \pm \varphi_{r}-\varphi_{Z h f}+\pi / 2\right)} \\
& Z_{h f}^{s}=r_{s}+j \omega_{h f}\left(L_{l s}+L_{m}\right)
\end{aligned}
$$

where $\left|Z_{h f}^{s}\right|$ is the magnitude of the stator high frequency impedance $\left(Z_{h f}^{s},(17)\right)$ and $\varphi_{Z_{h f}^{s}}$ is the phase of the stator high frequency impedance.

Assuming that $r_{s}<<\omega_{h f}\left(L_{l s}+L_{m}\right)$, the resulting stator high frequency current (15) can be simplified to (18), while the induced rotor high frequency voltage (16) can be simplified to (19).

$$
\begin{aligned}
& i_{d q h f_{-} s}^{s}=\frac{V_{h f}}{\left|Z_{h f}^{s}\right|} e^{j\left(\omega_{h t} t-\frac{\pi}{2}\right)} \\
& v_{d q h f_{-} r}^{s}=\frac{N_{r}}{N_{s}} \frac{V_{h f}}{\left|Z_{h f}^{s}\right|} L_{m} \omega_{h f} e^{j\left(\omega_{h f} t \varphi_{r}\right)} \\
& Z_{h f}^{s}=j \omega_{h f}\left(L_{l s}+L_{m}\right)
\end{aligned}
$$

It is concluded from (10) and (19) that it is possible to estimate the rotor position $\left(\varphi_{r}\right)$ from the phase angle between the injected stator high frequency voltage $\left(v_{\text {dqhf_s }}^{s}\right)$ and the resulting rotor high frequency voltage $\left(v_{\text {dahf } r}^{s}\right)$.

In high power machines, where the switching frequency of the power converter is low, it is possible that $r_{s}<<$ $\omega_{h f}\left(L_{l s}+L_{m}\right)$ will not hold since the frequency of the injected high frequency signal needs to be a submultiple of the switching frequency. It is seen from (10) and (16) that in this case, the stator high frequency impedance phase should be estimated and decoupled to obtain an accurate estimate of the rotor position. This parameter could be measured and stored in the DSP memory during a commissioning process.

Fig. 2 shows the grid-side-converter (GSC) and rotorside-converter (RSC) control block diagrams respectively, their operation is discussed following:

GSC: The grid side converter controls the dc bus voltage in the back-to-back converter, also can inject/absorb reactive power into/from the grid if needed, a current regulator synchronous with the grid voltage often being used for this purpose. The high frequency signal used for sensorless control in the GSC is added at the output of the current controller (see fig. 2). A band-stop filter is used in the current feedback control loop to prevent the fundamental current regulator reaction to the high frequency signal. In the proposed strategy, there are two modes of operation, namely Constant voltage mode and Limited current mode.

In the Constant voltage mode, a constant magnitude high frequency voltage is commanded (21). A high frequency PI voltage regulator in a reference frame synchronous with the injected high frequency voltage, $\omega_{h f}$ (22), is included to force the stator high frequency voltage to follow the commanded value $\left(v_{d q h f_{-} s}^{h f^{*}}\right)$. This regulator compensates for the voltage drop in the GSC output filter, which is affected by the grid impedance.

$$
\begin{aligned}
& v_{d q h f_{-} s}^{h f^{*}}=v_{d q h f_{-} s 0}^{h *^{*}} \text { if }\left|e_{i_{d q h f_{-} s} \mid}\right|>e_{t h} \\
& G_{H F V R}=k_{p_{-} v r}\left(1+K_{i_{-} v r} / s\right)
\end{aligned}
$$

where $e_{t h}$ is a threshold in the hysteresis for the transition between the Constant voltage mode and Limited current mode (see Fig. 2).

A problem with this mode of operation is that the resulting high frequency current is not controlled or limited, and might be too high in grids with low short circuit impedance, or even in the event of interferences among DFIGs using the method near to each other.

To prevent from this to occur, the Limited current mode is used. In this mode, the difference between the maximum value of the injected high frequency current allowed (e.g. permitted by the connection standards [23-25]) and the actual value is calculated using (23). If the high frequency current is too large, an integral controller is used to limit the injected high frequency voltage (24). This is schematically shown in Fig. 2.

Finally, it can be safely assumed that the stator high frequency impedance, (20), is much higher than the grid impedance. Since a small portion of the GSC high frequency current is injected into the machine, the high frequency current injected into the grid will be lower than the GSC high frequency current. Therefore, the high frequency current injected into the grid will be within the limits permitted by the connection standards provided that the GSC high 


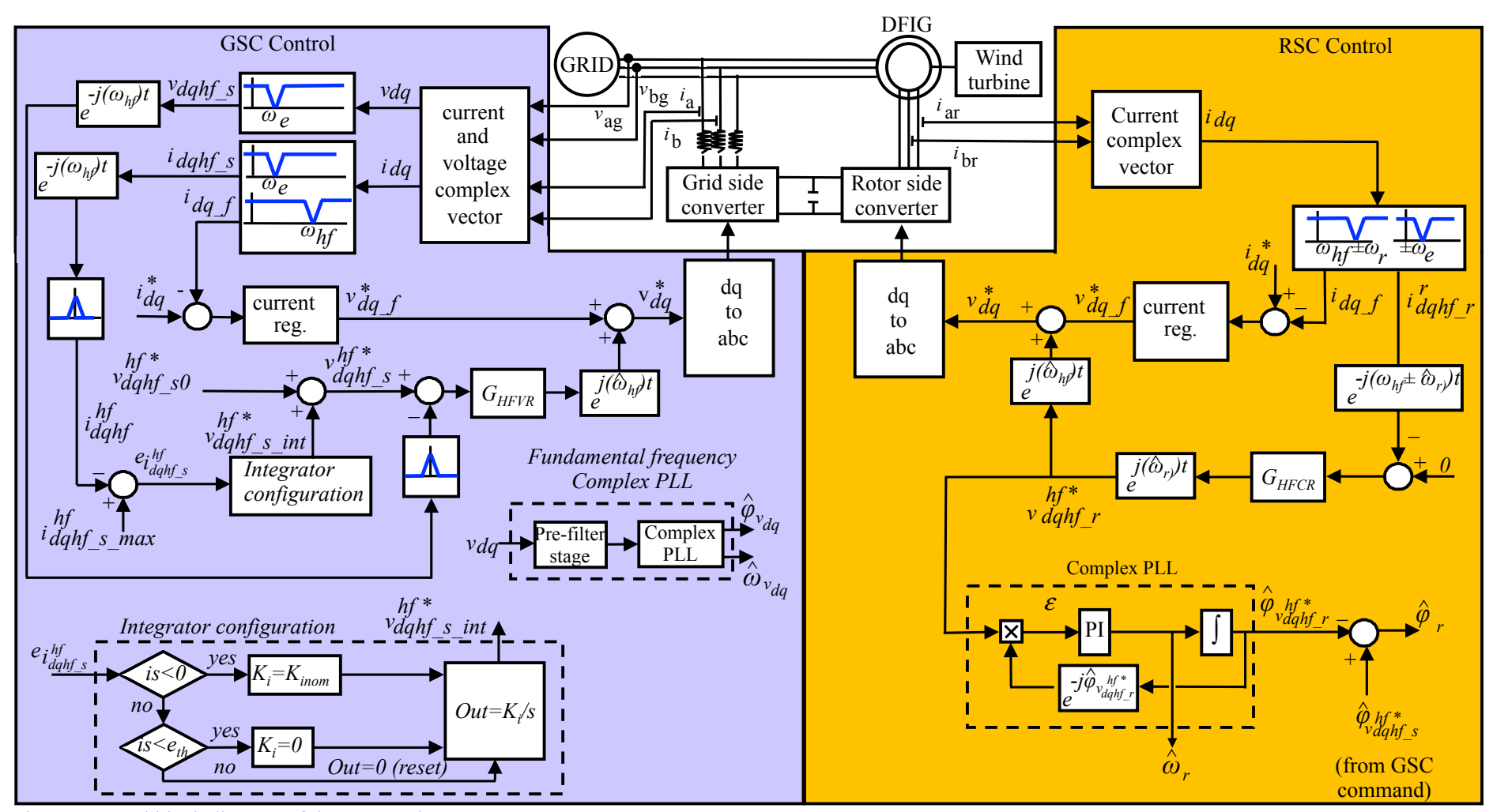

Fig. 2.- Control block diagram of the GSC and RSC.

frequency current is also within those limits [23-25].

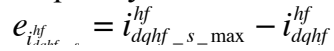

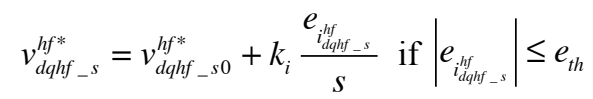

The integral action in (24) is reset if $\left|e_{i_{d a t f}, s}\right|>e_{t h}$, a hysteresis is used when $0<\left|e_{i_{\text {ihth }}^{\text {hi }}-s}\right|<e_{t h}$ to prevent continuous switching between the two modes of operation when $\left|e_{i_{d a t h f_{-}}}\right|$ is near zero.

RSC: Similar to the GSC, a current regulator is used to control the rotor fundamental current. The high frequency signal used for sensorless control is added at the output of the current controller (see fig. 2). A high frequency current regulator $G_{H F C R}$ (same design as (22)), is used to guarantee that no high frequency current circulates through the rotor by making its reference equal to zero.

Rotor position estimation; The rotor position is obtained as the phase angle difference between the stator high frequency voltage and the rotor high frequency current regulator $\left(G_{H F C R}\right)$ output voltage, as shown in Fig. 2 . The phase of the stator high frequency voltage is obtained from the high frequency voltage vector commanded by the GSC while the phase of the current regulator reaction is obtained from a complex phase-lock-loop (PLL) (see Fig. 2). The error signal for the complex PLL is obtained as the vector cross-product

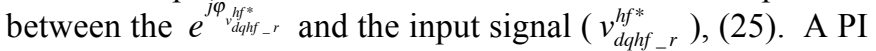
regulator is used to force this error to be equal to zero, the output of the regulator being therefore the estimated rotor speed, from which, by means of integration, the estimated rotor position is obtained (see Fig. 2).

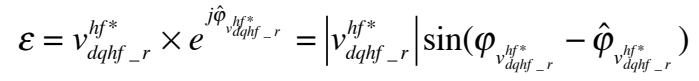

\section{IV.Simulation results.}

The proposed method has been simulated using the scenario shown in Fig. 1. Machine parameters, filters and regulator parameters (complex-PLL, current and voltage regulators) are shown at Table I. The switching frequency of both GSC and RSC is $10 \mathrm{kHz}$. The short-circuit power of the grid is 2MVA, with $r_{g} / X_{q} \approx 0.3 @ 50 \mathrm{~Hz}$.

A MPPT strategy was used to control the DFIG. Fig. 3a and $\mathrm{b}$ show the rotor $q$-axis current and the rotor speed response to a step-like change of the wind speed, while Fig 3c shows the phase error between the estimated position, using the signal processing described in section III (see Fig. 2), and the measured position of the machine. It is observed that the error in the estimated position is almost negligible even during the transient.

Fig. 4 shows the simulation results when at $t=0.9 \mathrm{~s}$ the short-circuit power of the grid (i.e. the grid impedance) changes from 2MVA to 200MVA, and the ratio $r_{g} / X_{g}$ changes from0.3 to $0.1 @ 50 \mathrm{~Hz}$. A slight transient is observed in the stator high frequency voltage when the change occurs (see Fig. 4a), which is corrected by the high frequency voltage regulator of the GSC control (see Fig. 3) in a few tenths of a second. Although the steady state position error is almost 
negligible, a slight increase of the transient position error is observed compared to the case shown in Fig. 3.

\begin{tabular}{|c|c|c|c|}
\hline \multicolumn{4}{|c|}{ TABLE I simulation parameters } \\
\hline \multicolumn{4}{|c|}{ Machine Parameters } \\
\hline$U_{\text {RATED }}(\mathrm{V})($ Stator) & 380 & $r_{s}(\Omega)$ & 0.416 \\
\hline$U_{\text {RATED }}(\mathrm{V})$ (Rotor) & 190 & $L_{l s}^{\prime}(\mathrm{mH})$ & 5 \\
\hline$I_{\text {RATED }}(\mathrm{A})$ (Stator) & 12.5 & $r_{r}^{\prime}(\Omega)$ & 0.75 \\
\hline$I_{\text {RATED }}(\mathrm{A})$ (Rotor) & 25 & $L_{l r}^{\prime}(\mathrm{mH})$ & 5.2 \\
\hline$f_{\text {RATED }}(\mathrm{Hz})$ & 50 & $L_{m}(\mathrm{mH})$ & 125.4 \\
\hline$P_{\text {RATED }}(\mathrm{kW})$ & 7.5 & $J\left(\mathrm{Kgm}^{2}\right)$ & 0.071 \\
\hline$\omega_{\text {RATED }}(\mathrm{rpm})$ & 1500 & GSC filter $(\mathrm{mH})$ & 1.074 \\
\hline \multicolumn{4}{|c|}{ Rotor Side Converter } \\
\hline \multicolumn{3}{|l|}{ BS-filter (Hz) } & 10 \\
\hline \multirow{2}{*}{\multicolumn{2}{|c|}{ Current Reg. }} & $K_{p c r}$ & 20 \\
\hline & & $K_{i c r}$ & 200 \\
\hline \multirow{2}{*}{\multicolumn{2}{|c|}{ CPLL }} & $K_{p}$ & 3 \\
\hline & & $K_{i}$ & 350 \\
\hline \multicolumn{3}{|c|}{ PWM and sampling frequency $(\mathrm{kHz})$} & 10 \\
\hline \multicolumn{4}{|c|}{ Stator Side Converter } \\
\hline \multicolumn{3}{|l|}{ BS-filter(Hz) } & 10 \\
\hline \multicolumn{3}{|l|}{ BP-filter(Hz) } & 20 \\
\hline \multirow{2}{*}{\multicolumn{2}{|c|}{ HF signal }} & $V_{h f}(\mathrm{pu})$ & 0.05 \\
\hline & & $\omega_{h f}(\mathrm{~Hz})$ & 500 \\
\hline \multirow{2}{*}{\multicolumn{2}{|c|}{ Voltage Reg. }} & $K_{p v r}$ & 6 \\
\hline & & $K_{i v r}$ & 160 \\
\hline \multicolumn{3}{|c|}{ PWM and sampling frequency $(\mathrm{kHz})$} & 10 \\
\hline
\end{tabular}

\section{Parallel operation of DFIGs}

The proposed method has been analyzed so far for the case of a single DFIG connected to a microgrid/grid. However this is not the typical situation in practice. Instead, wind turbines are often grouped in wind farms consisting of from a few up to several hundred wind turbines [26]. While the implementation of the proposed method is relatively simple when a single DFIG exist, interferences among DFIGs can occur if several parallel-connected DFIGs simultaneously inject the high frequency signal for speed/position control, as this might produce interference and lead in the end to erroneous position/speed estimations. Strategies to prevent interference among DFIGs need therefore to be considered.

A simple strategy to prevent interference would be to use a different frequency for the high frequency signals for each DFIG. The method has however some significant limitations. It requires to pre-set the frequency for each DFIG, what might not be viable when the number of DFIGs is high. Also the THD in the grid currents due to the injection of the high frequency signals would increase as the number of parallelconnected DFIGs increase. Finally, the filtering needed to isolate the stator and rotor high frequency components (see Fig. 2) will be more difficult if a large number of carrier signals, at frequencies relatively close to each other, exist.

In the strategy proposed in this paper, all the DFIGs inject the same high frequency signal (frequency, magnitude and phase). By doing this, no high frequency current will flow among DFIGs, avoiding therefore interferences. A method for doing this is making the high frequency signal to be an integer multiple of the grid frequency ( $\widehat{\omega}_{v d q}$ in Fig. 2 ). A PLL
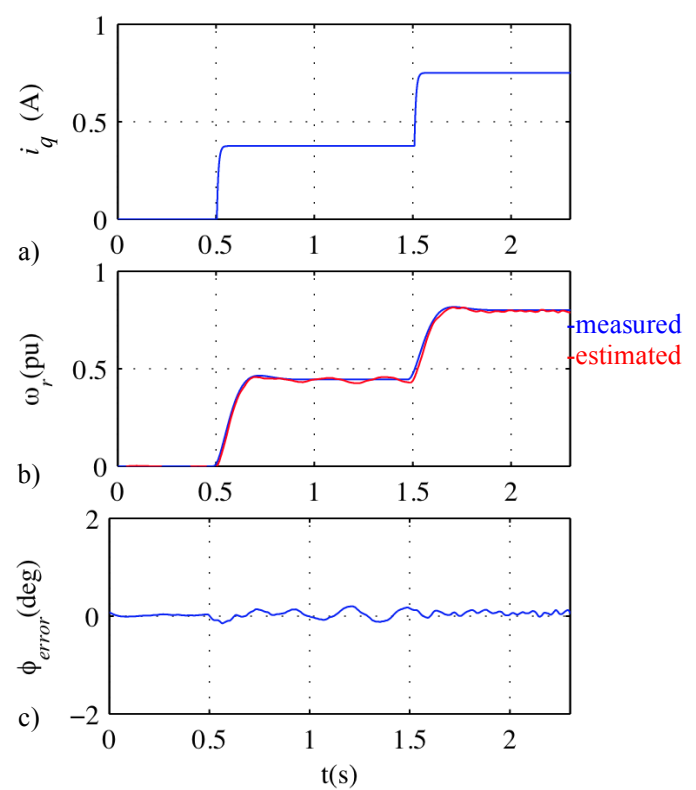

Fig. 3.- Simulation results. a) Injected $I_{q}$ rotor current, b) machine speed and c) position error. $V_{h f}=0.05 \mathrm{pu}, \omega_{h f}=500 \mathrm{~Hz}$.

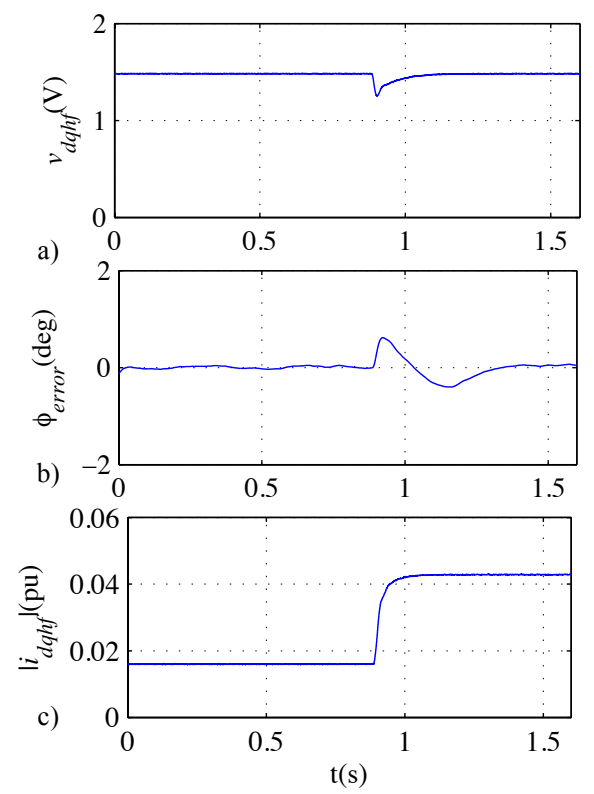

Fig. 4.- Simulation results when a change of the grid short-circuit power from 2MVA to 200MVA occurs $(\mathrm{t}=0.9 \mathrm{~s})$. a) Stator high frequency voltage, b) position error and c) GSC output high frequency current. $V_{h \mathrm{f}}=0.05 \mathrm{pu}, \omega_{h f}=500 \mathrm{~Hz}$ and $\omega_{r}=40 \mathrm{~Hz}$.

can then be implemented in each DFIG to guarantee their synchronization. A scheme of the synchronization technique that is used in this paper to obtain the frequency $\widehat{\omega}_{v d q}$ and phase $\hat{\varphi}_{v d q}$ of the fundamental voltage is shown in Fig. 2. The details can be found in [27]. IT is finally noted that any other synchronizations technique could be used.

A simple scenario for the simulation with two DFIGs connected in parallel is shown in Fig. 5. The two DFIGs are connected to the utility grid throughout a point of common 
coupling (PCC). The line parameters are $\mathrm{R}=10.7 \mathrm{~m} \Omega$ and $\mathrm{L}=0.668 \mathrm{mH}$, for line $1, \mathrm{R}=8 \mathrm{~m} \Omega$ and $\mathrm{L}=0.594 \mathrm{mH}$, for line 2 .

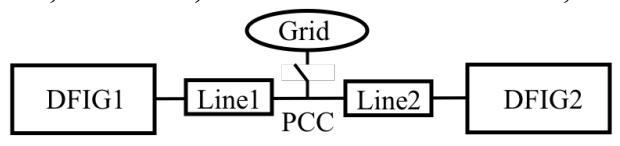

Fig. 5.- Simulation scenario for two parallel-connected DFIGs.

Fig. 6 shows the simulated response when DFIG \#1 is continuously injecting and DFIG \#2 injects the high frequency signal form $t=0.5 \mathrm{~s}$ to $\mathrm{t}=1.5 \mathrm{~s}$; both high frequency signals are synchronized (same frequency, magnitude and phase). Fig. 6b shows the estimated position error of DFIG \#1. It is observed that the steady state position error is almost negligible, although a transient increase of the position error is observed when DFIG \#2 begins and finishes injecting the high frequency signal, the transient errors being function of the GSC and RSC high frequency voltage and current regulators, $G_{H F C R}$ and $G_{H F V R}$ respectively. It is also observed from Fig. $6 \mathrm{c}$ that the circulating high frequency current $\left(i_{d q h f c}\right)$ between both converters is negligible.

In general, it is advantageous to synchronize the high frequency signals injected by the DFIGs. This can be easily done by choosing the high frequency to be an integer multiple of the grid frequency. However, the possibility of asynchronous injection, due e.g. to transient errors in the PLLs estimating the grid voltage angle, should be considered.

Fig. 7 shows the same simulation results as Fig. 6, but with a phase shift between the injected high frequency signals of $90 \mathrm{deg}$. It is observed from Fig. 7a that both DFIG \#1 and \#2 decrease the magnitude of the injected signal due to the limit imposed for the high frequency current $\left(i_{d q h f_{-} s_{-} \max }^{h f}=0.045 \mathrm{pu}\right.$, see Fig. 2). If DFIG $\# 1$ and $\# 2$ detect that the injected high frequency current is bigger than $i_{d q h f_{-} s_{-} \max }^{h f_{1}}$ (see Fig. 7c), both DFIGs change their mode of operation, decreasing the magnitude of the injected high frequency signal (24) to reach that limit (see Fig. 7a and c). It is also noted that a circulating high frequency current exists due to the lack of synchronization between the high frequency signals (see Fig. $7 \mathrm{c})$.

Fig. 8a shows the PCC high frequency voltage magnitude when DFIG \#1 and \#2 are injecting a signal of the same magnitude and frequency, but with a phase shift. Fig. 8b shows the high frequency current injected into the grid, while Fig. $8 \mathrm{c}$ shows the circulating currents between DFIG \#1 and \#2. It is observed that the maximum value of the circulating high frequency current between converters and the minimum grid high frequency current magnitude is reached when the phase shift between the high frequency signals is $180^{\circ}$, while the minimum circulating high frequency current between converters and the maximum grid high frequency current is reached for a phase shift of $0^{\circ}$.
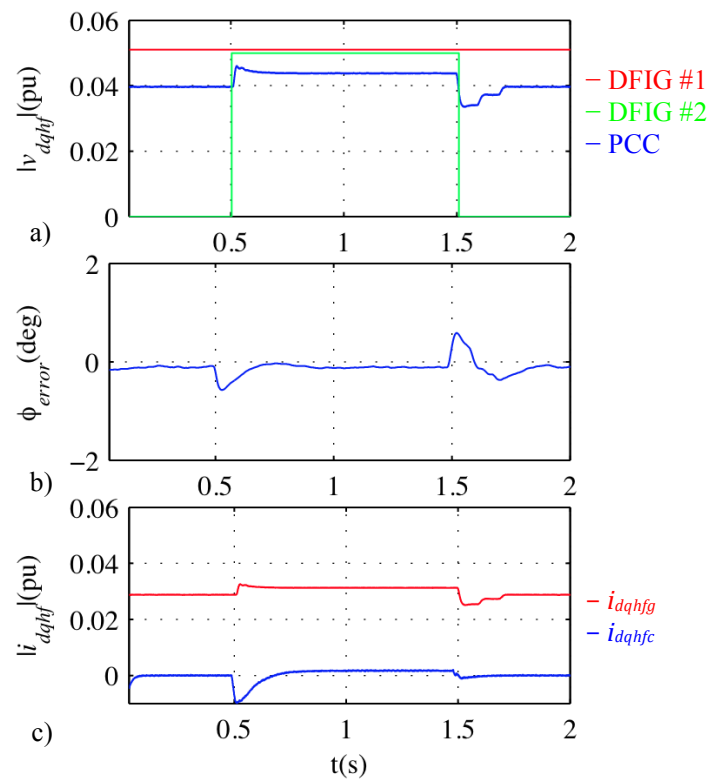

Fig. 6.- Simulation results when DFIG \#1 is injecting the high frequency signal continuously and DFIG \#2 injects the high frequency signal from $0.5<\mathrm{t}<1.5 \mathrm{~s}$. a) PCC high frequency voltage and commanded high frequency signals magnitudes, b) estimated position error for DFIG \#1 and c) circulating high frequency current between DFIGs, $i_{d q s h}$, and high frequency current injected into the grid, $i_{d q s h g} . V_{h f}=0.05 \mathrm{pu}, \omega_{h f}=500 \mathrm{~Hz}$, $\omega_{r}=40 \mathrm{~Hz}$ and phase shift between the injected high frequency signals 0 deg..
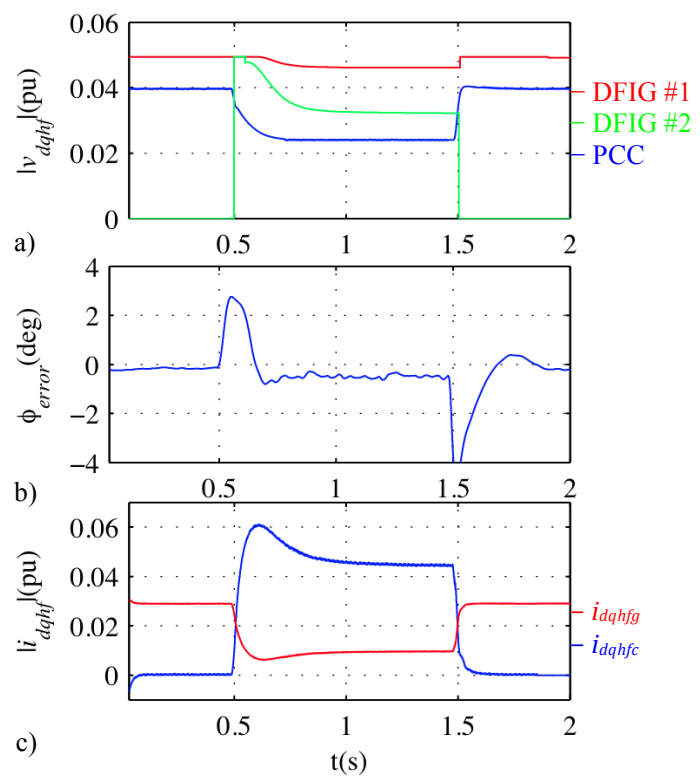

Fig. 7.- Same variables an operating condition as Fig. 6 but with a phase shift between the injected high frequency signals of $90 \mathrm{deg}$. 

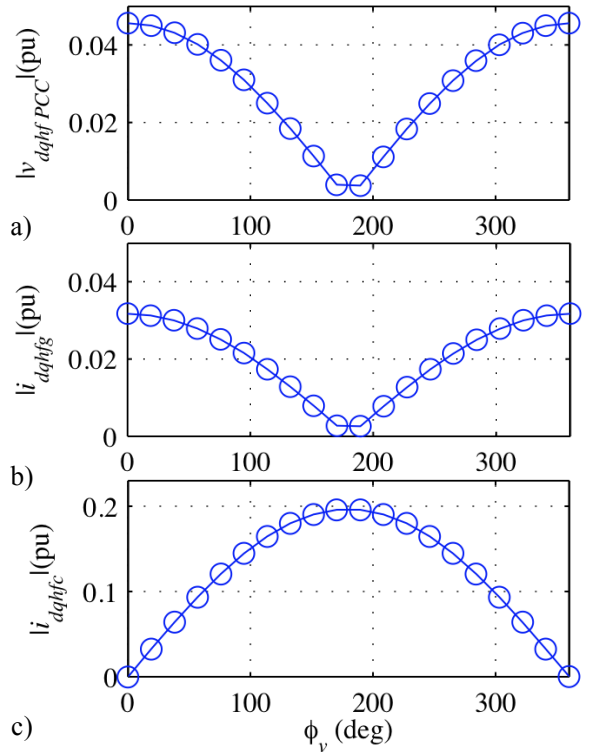

Fig. 8.- a) PCC high frequency voltage magnitude, b) grid high frequency current magnitude, and c) circulating high frequency current magnitude between the DFIGs vs. the phase shift between the two injected high frequency signals, $\phi_{v} . V_{h f}=0.05 \mathrm{pu}, \omega_{h f}=500 \mathrm{~Hz}$.

\section{Experimental results}

Experimental results showing the validity of the proposed method are presented in this section. Fig. 9 shows the experimental setup. The parameters of the test machine are the same as for simulations (see Table I). The wind turbine (see Fig. 1) is emulated by means of a vector controlled IM (see Fig. 9). Table II shows the filters, regulator (voltage and current) and complex-PLL parameters. It is noted that the frequency of the injected high frequency signal used for the experiments has been increased with respect to the simulations. This is due to the fact that using lower frequencies in simulation allowed increasing the simulation time step, significantly reducing therefore the simulation time. In general, higher frequencies would be preferred, since this will make the impedance of the machine more inductive, therefore making the assumption that $r_{s}<<$ $\omega_{h f}\left(L_{l s}+L_{m}\right)$ safer.

TABLE II experimental results parameters Rotor Side Converter

\begin{tabular}{|l|l|l|}
\hline BS-filter (Hz) & \multicolumn{2}{|l|}{ Rotor Side Converter } \\
\hline \multirow{2}{*}{ Current Reg. } & $K_{p c r}$ & 20 \\
\cline { 2 - 3 } & $K_{i c r}$ & 200 \\
\hline \multirow{2}{*}{ CPLL } & $K_{p}$ & 4.2 \\
\cline { 2 - 3 } & $K_{i}$ & 435 \\
\hline PWM and sampling frequency (kHz) & 10 \\
\hline \multicolumn{2}{|c|}{ Stator Side Converter } \\
\hline BS-filter(Hz) & 10 \\
\hline BP-filter(Hz) & $V_{h f}(\mathrm{pu})$ & 10 \\
\hline \multirow{2}{*}{ HF signal } & $\omega_{h f}(\mathrm{~Hz})$ & 0.05 \\
\hline \multirow{2}{*}{ Voltage Reg. } & $K_{p v r}$ & 1000 \\
\cline { 2 - 3 } & $K_{i v r}$ & 10 \\
\hline PWM and sampling frequency (kHz) & 230 \\
\hline
\end{tabular}


important to note that the speed changes used for this experiment (see Fig. 10a) are significantly faster than those expected in a real wind turbine, what would make these transient effects less important in practice.
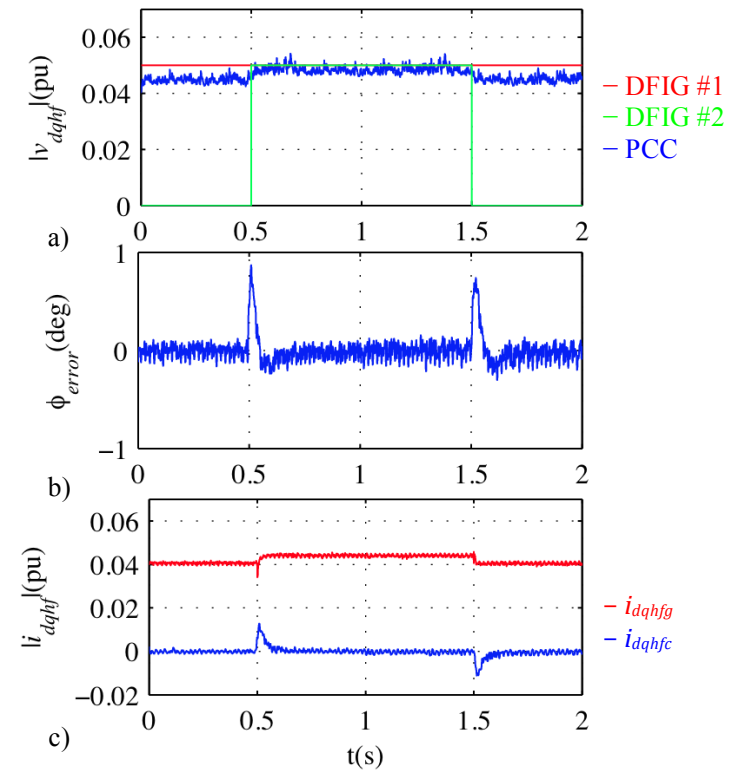

Fig. 12.- Experimental results showing the response of the proposed method when DFIG \#1 is injecting the high frequency signal continuously and inverter (DFIG \#2) injects the high frequency signal during $0.5<\mathrm{t}<1.5 \mathrm{~s}$. a) PCC high frequency voltage and commanded high frequency signals magnitudes, $b$ ) estimated position error (DFIG \#1), and c) circulating high frequency current between DFIG \#1 and the inverter and circulating high frequency current to the grid. $V_{h f}=0.05 \mathrm{pu}, \omega_{h f}=1000$ $\mathrm{Hz}, \omega_{r}=0.3 \mathrm{pu}$ and phase shift between the injected high frequency signals 0deg..
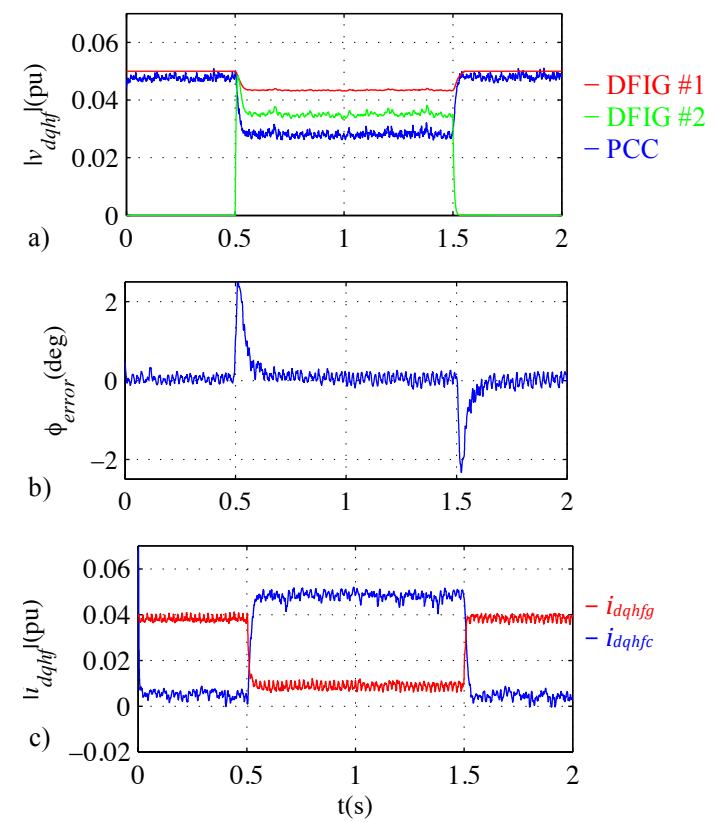

Fig. 13.- Same variables an operating condition as Fig. 12 but with a phase shift between the injected high frequency signals of $90 \mathrm{deg}$.

For the verification of the proposed method when multiple DFIG are connected to the grid, a power converter synchronized to the utility grid was used to emulate the behavior of the GSC of the second DFIG (DFIG \#2). This is shown in Fig. 11.

Fig. 12 shows the experimental results when DFIG \#1 injects the high frequency signal continuously, and the inverter that accounts for DFIG $\# 2$, injects from $\mathrm{t}=0.5$ to $\mathrm{t}=1.5 \mathrm{~s}$. Both high frequency signals have the same magnitude, frequency and phase angle. Fig. 12a shows the high frequency voltage magnitude at the PCC and the commanded high frequency signals by DFIG \#1 and DFIG \#2. Fig. 12b shows the position error, while Fig. 12c shows the circulating high frequency currents between converters and the high frequency current injected into the grid.

Fig. 13 shows the same experimental results as Fig. 12, but with a phase shift between the injected high frequency signals of $90 \mathrm{deg}$. As in the simulation results, it is observed from Fig. 13a that both DFIG \#1 and \#2 decrease the magnitude of the injected signal due to the limit imposed to the high frequency current $\left(i_{\text {dqhf_s } \max }^{h f}=0.045 \mathrm{pu}\right)$. Also circulating high frequency current exists due to the lack of synchronization between the high frequency signals (see Fig. $13 c)$.
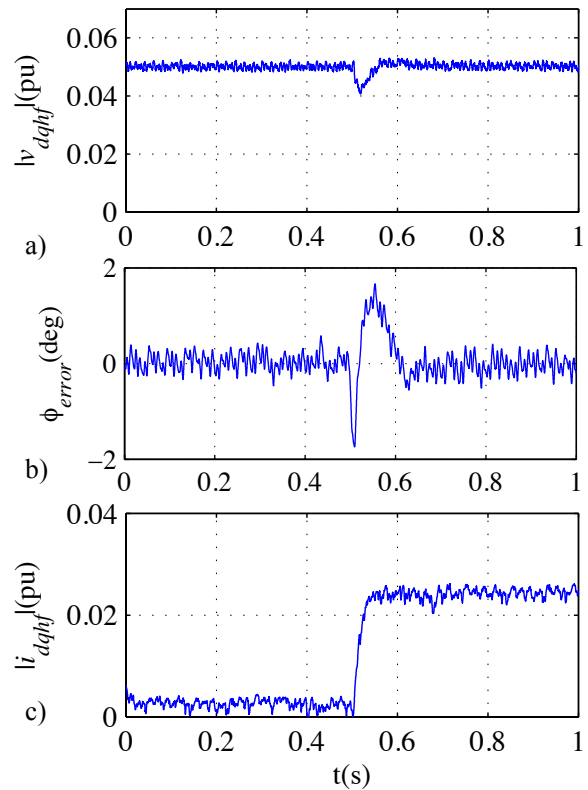

Fig. 14.- Experimental results showing the response of the propose method when a change of the grid short-circuit power from 0.1MVA to 2MVA occurs $(\mathrm{t}=0.5 \mathrm{~s})$. a) Stator high frequency voltage magnitude, $\mathrm{b})$ position error and c) GSC output high frequency current. $V_{h \mathrm{f}}=0.05 \mathrm{pu}, \omega_{h f}=1000 \mathrm{~Hz}$ and $\omega_{r}=0.3 \mathrm{pu}$.

Fig. 14 shows the experimental results when the short circuit power of the grid changes form 0.1 MVA to 2 MVA, while the ratio $r_{g} / X_{g}$ changes from 1 to $0.4 @ 50 \mathrm{~Hz}$. A slight transient variation of the stator high frequency voltage magnitude (see Fig. 14a) and of the position error (see Fig. $14 \mathrm{~b}$ ) is observed when the short circuit power of the grid changes. Also an increase of the output GSC high frequency current is observed due to the increase of the short circuit 
power (see Fig. 14c). The stator high frequency voltage transient variation is compensate by the high frequency voltage regulator of the GSC control (see Fig. 2), the transient increase of the position error being depending on the transient response of both the stator high frequency voltage regulator and the rotor high frequency current regulator (see Fig. 2).

\section{Conclusions}

This paper proposes the use of a high frequency signal injection method for sensorless control of DFIGs in wind power generation. The proposed method combines high frequency voltage injection in the stator with high frequency current cancellation in the rotor. The rotor position is estimated from the phase shift between the injected stator high frequency voltage complex vector and the resulting rotor high frequency current regulator reaction. The distinguishing characteristic of the stator high frequency signal injection compared with the rotor injection is that the sensorless control method is independent of the grid characteristics. Simulation and experimental results have been provided to confirm the viability of the proposed method.

\section{VIII.References.}

[1] P. Cheng and H. Nian, "An Improved Control Strategy for DFIG System and Dynamic Voltage Restorer under Grid Voltage Dip", IEEE-ISIE, pp. 1868-1873, 2012.

[2] Spain's National Renewable Energy Action Plan 2011-2020, Spanish ministry of industry, tourism and trade. Available: http://ec.europa.es/energy.

[3] US's National Action Plan for Energy Efficiency. Available: http://www.epa.gov.

[4] A. Luna, F. K. A. Lima, D. Santos P. Rodriguez, E. H. Watanabae and S. Arnaltes, "Simplified Modeling of a DFIG for Transient studies in Wind Power Applications," IEEE Trans. Ind. Elec., vol. 58 (1), pp. 920, Jan. 2011.

[5] L. Xu and Y. Wang, "Dynamic Modeling and Control of DFIG-Based Wind Turbines Under Unbalanced Network Conditions," IEEE Power Sys., vol. 22 (1), pp. 314-324, Feb. 2007.

[6] D. Reigosa, F. Briz, C. Blanco, A. Di Gioia, P. Garcia and J.M. Guerrero, "Sensorless Control of Doubly-Fed Induction Generator Based on Rotor High Frequency Signal Injection," IEEE-ECCE'12, pp. 2268-2275, Sept. 2012

[7] R. Pena, J.C. Clare and G. M. Asher, "Doubly Fed Induction Generator Using Back-to-Back PWM Converters and its Application to Variable Speed Wind Energy Conversion", IEE Proc. Elect. Power Appl., vol. 143 (5), pp. 380-387, Sept. 1996.

[8] P.L. Jansen and R.D. Lorenz, "Transducerless position and velocity estimation in induction and salient AC machines," IEEE Trans. Ind. Appl., Vol. 31, pp. 240-247, Mar./Apr. 1995.

[9] L. A. de S. Ribeiro, M.C. Harke, and R.D. Lorenz, "Dynamic Properties of Back-emf Based Sensorless Drives," IEEE-IAS, Vol. 4, pp. 2026 - 2033, Oct 2006.

[10] P. P. Acarnely and j. F. Watson, "Review of Position-Sensorless Operation of Brushless Permanent-Magnet Machines," IEEE Trans. Ind. Electron., vol. 53 (2), pp. 352-362, Apr. 2006.

[11] S. Ogasawara and H. Akagi, "Approach to real-time position estimation at zero and low speed for a PM motor based on saliency," IEEE Trans. Ind. Appl., vol. 34, pp. 163-168, Jan.-Feb. 1998.

[12] J. Holtz and H. Pan, "Acquisition of rotor anisotropy signals in sensorless position control systems," IEEE Trans. Ind. Appl. , Sept./Oct. 2004, Vol. 40, No 5, pp. 1379-1387.

[13] P. García, F. Briz, M.W. Degner, D. Díaz-Reigosa, "Accuracy and Bandwidth Limits of Carrier Signal Injection-Based Sensorless Control Methods", IEEE Trans. Ind. Appl., Vol. 43 (4), pp. 990-1001, July/Aug. 2007.
[14] D. Reigosa, P. García, D. Raca, F. Briz, and R.D. Lorenz, "Measurement and Adaptive Decoupling of Cross-Saturation Effects and Secondary Saliencies in Sensorless-Controlled IPM Synchronous Machines," IEEE Trans. Ind. Appl., Vol. 44 (6), pp. 1758-1768, Nov./Dec. 2008.

[15] D. Reigosa, P. García, F. Briz, D. Raca and R.D. Lorenz, "Modeling and adaptive decoupling of transient resistance and temperature effects in carrier-based sensorless control of PM synchronous machines," IEEE Trans. Ind. Appl., Vol. 46 (1), pp. 139-149, Jan./Feb. 2010.

[16] D. Raca, P. García, D. Reigosa, F. Briz, and R.D. Lorenz, "Carrier Signal Selection for Sensorless Control of PM Synchronous Machines at Very Low and Zero Speeds," IEEE Trans. Ind. Appl., Vol. 46 (1), pp. 167-178, Jan./Feb. 2010.

[17] Y. Yoon, S. Sul, S. Morimoto and K. Ide, "High Bandwidth Sensorless Algorithm for AC Machines Based on Square-wave Type Voltage Injection," IEEE Trans. Ind. Appl., Vol. 47 (3), pp. 1361-1379, May/June 2011.

[18] L. Xu, E. Inoa, Y Liu and B. Guan, "A New High Frequency Injection Method for Sensorless Control of Doubly-Fed Induction Machines," IEEE Trans. Ind. Appl., Vol. 48 (5), pp. 1556-1565, Sept./Oct. 2012.

[19] B. Shen, B. Mwinyiwiwa, Y Chang and B.T. Ooi "Sensorless Maximum Power Point Tracking of Wind by DFIG Using Rotor Position Phase Lock Loop (PLL)", IEEE Trans. Power Elect., vol. 24 (4), pp. 942-951, Apr. 2009.

[20] R. Cardenas, R. Peña, J. Proboste, G. Asher and J. Clare, "MRAS Observer for Sensorless Control of Standalone Doubly Fed Induction Generators", IEEE Trans. Energy Conv., vol. 20 (4), pp. 710-718, Dec. 2005.

[21] S. Yang and Venkataramana Ajjarapu, "A Speed-Adaptive ReducedOrder Observer for Sensorless Vector Control of Doubly Fed Induction Generator-Based Variable-Speed Wind Turbines", IEEE Trans. Energy Conv., vol. 25 (3), pp. 891-900, Sept. 2010.

[22] D. W. Novotny and T. A. Lipo, "Vector Control and Dynamics of AC Drives," Oxford Science Publications, 1996.

[23] IEC 61400-21, Measurement and assessment of power quality characteristics of grid connected wind turbines, International Electrotechnical Commission.

[24] IEC 61000-3-2, Limits for Harmonic Current Emissions, International Electrotechnical Commission.

[25] IEC 61000-3-6, Harmonic Emission Limits for Customers Connected to $M V, H V$ and $E H V$, International Electrotechnical Commission.

[26] IEEE 1547, Standard for Interconnecting Distributed Resources with Electric Power Systems.

[25] EWEA, Generic Grid Code Format for Wind Power Plants, The European Wind Energy Association.

[26] J. L. Rodríguez-Amenedo, S. Arnalte and J. C. Burgos, "Automatic Generation Control of a Wind Farm With Variable Speed Wind Turbines", IEEE Trans. Energy Conv., vol. 17 (2), pp. 279-284, Sept. 2002 .

[27] C. Blanco, D. Reigosa, F. Briz, J. M. Guerrero and P. Garcia, "Grid synchronization of three-phase converters using cascaded complex vector filter PLL", IEEE-ECCE'12, pp. 196 -203, Sept. 2012.

[28] R. Cárdenas, R. Peña, S. Alepuz and G. Asher, "Overview of Control Systems for the Operation of DFIGs in Wind Energy Applications", IEEE Trans. Ind. Electr., vol. 60 (7), pp. 2776-2798, July 2013. 